\title{
Modelling the Horizontal Velocity Field of the Nizhne-Kansk Massif According to GNSS Observations
}

\author{
Alexandr Manevich \\ Laboratory of Geodynamics \\ Geophysical Center RAS \\ Moscow, Russia \\ ai.manevich@yandex.ru \\ Danil Urmanov \\ Laboratory of Geodynamics \\ Geophysical Center RAS \\ Moscow, Russia \\ durmanov.dui@mail.ru
}

\author{
Vladimir Kaftan \\ Laboratory of Geodynamics \\ Geophysical Center RAS \\ Moscow, Russia \\ kaftan@geod.ru
}

\author{
Roman Shevchuk \\ Laboratory of Geodynamics \\ Geophysical Center RAS \\ Moscow, Russia \\ shevchuk.002@mail.ru
}

\begin{abstract}
Within the boundaries of the Nizhne-Kansk granite-gneiss massif, which directly borders on the Atamanovskiy branch of the Yenisei Ridge, the building of an underground research laboratory for validating the safety of disposal of high-level radioactive waste began in 2019. In 2010, researchers of the Mining and Chemical Combine at Zheleznogorsk and the Geophysical Center, Russian Academy of Sciences, organized a satellite geodetic network within the boundaries of the Nizhne-Kansk massif; this network included 30 GNSS stations intended for observations of modern crustal movements.
\end{abstract}

The purpose of this study is to determine vectors and simulate the field of horizontal modern crustal movements from measurements made in 2010 - 2019. The tasks included: creating a catalogue of displacement data; calculating and estimating horizontal velocities of modern crustal movements, modelling the horizontal velocity field using artificial neural networks, developing a kinematic model of the area and comparing it with geological survey data.

As a result, the resulting model was found to be in good agreement with the results of structural-geological and geodynamic studies in the area. The rate of convergence between the Siberian Platform and the West Siberian Plate in the interaction zone of the southern part of the Yenisei Ridge can be estimated as $2-4 \mathrm{~mm} /$ year. The movements of the selected area are due to sublatitudinal compression along an azimuth of 100-110 degrees. Within the selected tectonic blocks relatively low rates of modern horizontal movements of the earth's crust were obtained, which confirms the stable geodynamic regime of the structural block hosting the underground research laboratory. Thus, the results of the work demonstrate the possibility of disposal of high-level radioactive waste in the selected structural block.

Keywords - GNSS, modern crustal movements, horizontal velocity, modelling field, Nizhne-Kansk massif, Yenisei Ridge, radioactive waste

\section{INTRODUCTION}

At present, due to the development of nuclear power and nuclear technology, the problem of isolation of highlevel radioactive waste is more urgent than ever in the world. Today, most researchers and international organizations agree that the best solution to this problem, taking into account the modern technological development of mankind, is to create special deep underground storage facilities in which long-lived high-level radioactive waste (RAW) will be reliably isolated for the entire period of its potential danger.

In 2019, the construction of the first and only deep disposal facility for radioactive waste in Russia began in Krasnoyarsk region. By 2025, the plan is to complete construction of the underground research laboratory and begin a ten-year research program on the selected site [1].

The operation of underground RAW containment facilities is impossible without a comprehensive and longterm study of the geological massif. One of the key aspects of long-term safety of RAW isolation in geological formations is the low risk of development of destructive

\section{Online ISSN 2256-070X


geodynamic phenomena and processes, primarily such as earthquakes, faulting and modern crustal movements.

The development of hazard geodynamic processes and phenomena is determined by the laws of the stress and strain state of the studied subsurface area. Observations of modern crustal movements of the Earth's crust allow us to obtain the necessary data to study the geodynamic regime of the area and to assess the engineering criteria for the safe operation of the underground RAW isolation facility.

The organization of deformation monitoring is conditioned by the necessity to control modern movements and deformations of the Earth's crust. Currently, global navigation satellite systems (GNSS) are considered the most promising technology for these tasks, especially in combination with ground-based geological and geophysical methods and remote sensing. Particular importance is given to increasing the reliability and their analysis under conditions of insufficient instrumental data. The methodology of collection and high-precision processing of observations, as well as the program of observations of the modern crustal movements in the area of Nizhne-Kansk massif were developed at the laboratory of geodynamics of the Geophysical Center of the Russian Academy of Sciences [2-3].

The purpose of this work is to summarize the results obtained earlier, namely, the determination of vectors and modeling the field of modern horizontal movements of the Earth's crust based on the results of measurements carried out in 2012 - 2019 [3-4].

The insufficient amount of data for monitoring for modern crustal movements at the local geodynamic polygon, expressed in a small number of measurement points, geometric heterogeneity of geodetic networks, irregular in time data, as well as a drop in the quality of instrumental measurements, worsens the quality of information on the deformation of the earth's surface from remote places of the polygon. Either subsequent calculations based on the data obtained from the network can lead to a large loss of accuracy in determining displacements and deformation components, and hence to an increase in the unreliability of the resulting estimates and predictions [5-7]. To obtain regular, gridded data on earth surface deformations, it is necessary to use methods of mathematical modeling of displacement fields. Development of new methods and increasing the reliability of modeling displacement fields allows us to solve the problem of insufficient amount of deformation monitoring data.

\section{MATERIALS AND METHODS}

In order to observe the modern movements of the Earth's crust in this area, geodetic points were laid out to make measurements using GNSS methods. The measuring network was laid in such a way as to cross all the main local tectonic disturbances, to cover the territory of the construction site and regional tectonic structures. After processing the results of geodetic measurements were used time series (fig. 1) displacements for 23 geodetic points. The figure (fig. 2) shows a scheme of points of the used points, for which the estimation of horizontal velocities in the work [4] was carried out.

In figure 2 the area of the contour of the used geodetic network (blue line) and the area on which the estimation of movements and deformations of the Earth crust (purple line) is necessary is allocated. Because of the complex local physical and geographical conditions about $2 / 3$ of the entire area is outside the contour of the measurement network, and therefore for this area is impossible. obtain the values of movements and deformations of the earth's surface.
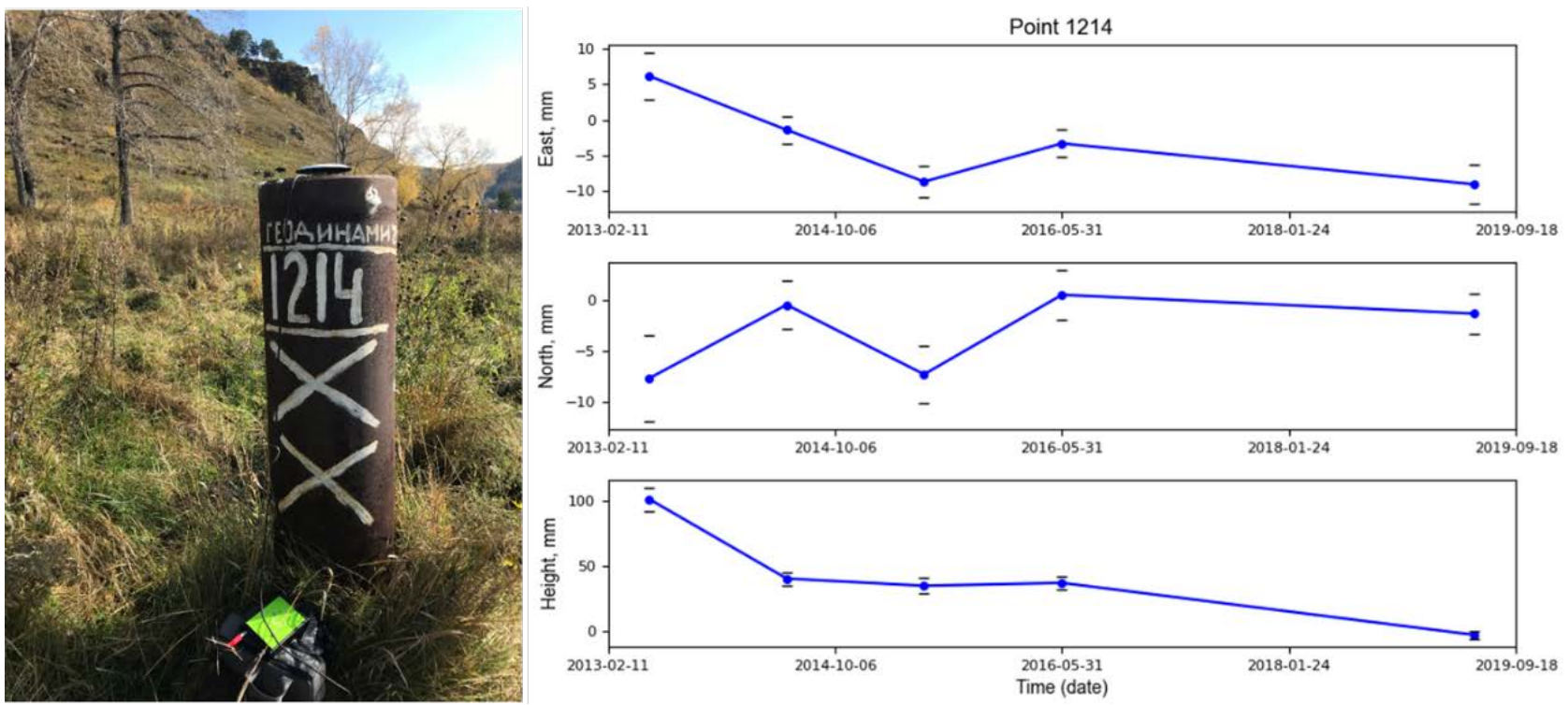

Fig. 1. Time series of displacement of point 1214 . 


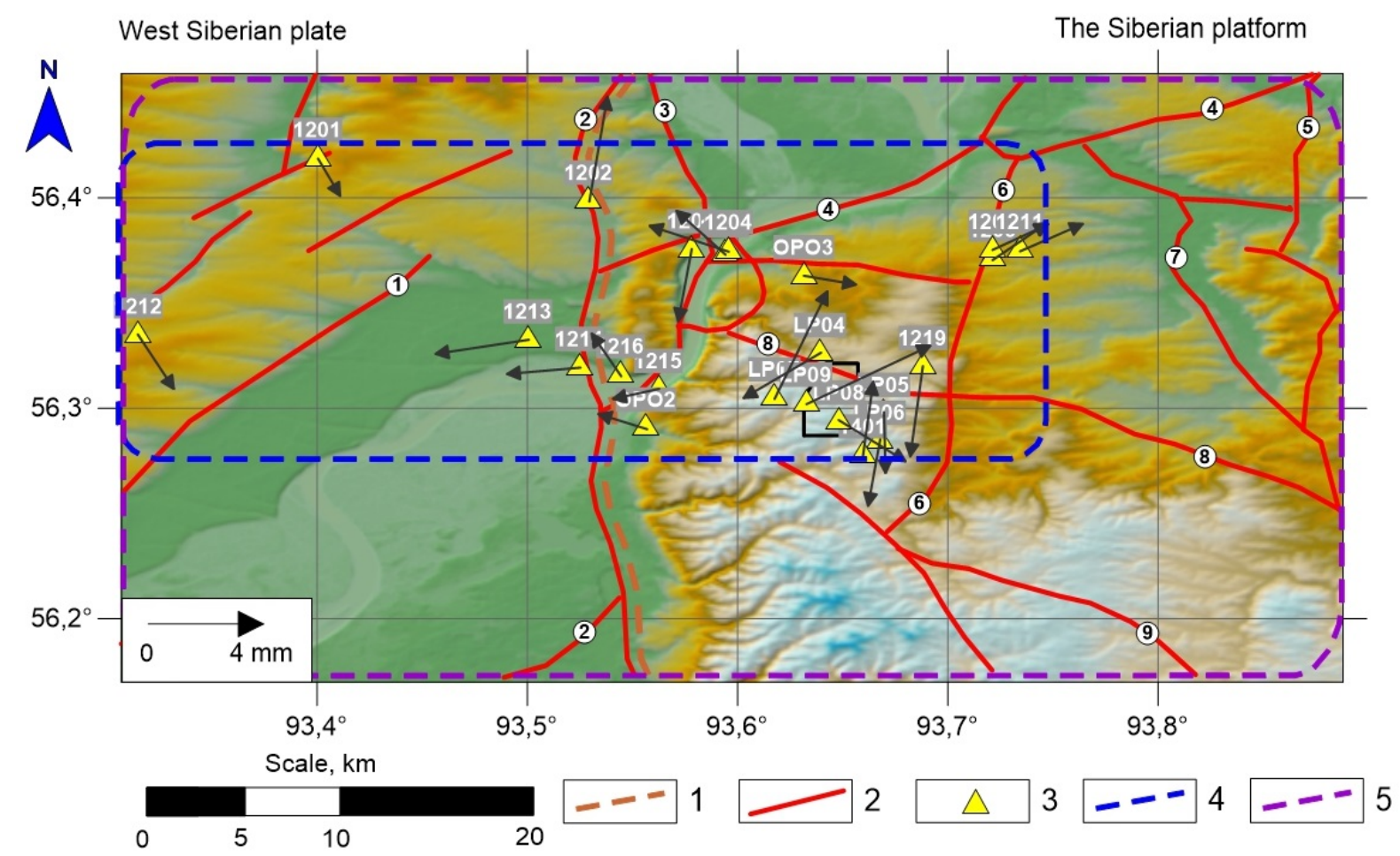

Fig. 2. The scheme of geodynamic polygon of Nizhne-Kansk massif. 1 - contact boundary of Siberian platform and West Siberian plate; 2 - tectonic faults; 3 - GNSS points; 4 - contour of geodetic network; 5 - area where forecast is required. The numbers in Figure 2 indicate major tectonic faults: 1 - First Krasnoyarskiy fault; 2 - Muratovskiy fault; 3 - Atamanovskiy fault; 4 - Kansko-Atamanovskiy fault; 5 - Malotel'skiy fault; 6 - Pravoberezhnyy fault; 7 - Bol'shetel'skiy fault; 8 - Shumikhinskiy fault; 9 - Baykal'skiy fault. The URL construction site is shown as a rectangle.

In this regard, it is necessary to obtain the values of velocities and displacements to the nodes of the regular network before the deformation analysis of the data. This requires extrapolating the raw data to obtain regular grid data.

Artificial neural networks were used for spatial extrapolation of the data. This algorithm is a layered system of connected and interacting simple processors (neurons). Each neuron of the network deals only with the signals it receives and the signals it sends to other neurons. When connected into a sufficiently large network, such individually simple neurons together are able to perform quite complex tasks. The network has interconnections between neurons, and the strength of these interconnections is expressed by certain weight coefficients. The full matrix of such weights and input and output signals of neurons, in fact, is the solving apparatus of this method.

In the example under consideration, the prediction of displacements and velocities of movements was spatial, carried out at a certain point in time. Incoming data (signals) were coordinates and terrain indicators. The structure of the neural network was chosen as follows - 5 neurons in the hidden layer ( 2 hidden layers), 1 neuron in the output layer (Fig. 3). Since the displacement can take both positive and negative values, the hyperbolic tangent was chosen as the activation function. The following metrics were chosen to assess the quality of the results of the algorithm's predictions:

Mean Absolute Error (MAE) shows the average absolute deviation of the predicted displacements from the true ones. The application of absolute deviation is due to the fact that the values of displacements can be both positive and negative. MAE is determined by formula 1 :

$$
\mathrm{MAE}=\frac{1}{n} \sum_{i=1}^{n}\left|U_{i}-a_{i}\right|
$$

where $\mathrm{n}$ is the number of points in the used sample (training, test, control);

$U_{i}$ - value of the measured displacement;

$a_{i}$ - value of the predicted displacement.

The Sum Absolute Error (SAE) shows the total absolute deviation of the predicted offsets from the true offsets. Gives an estimate of the integral cumulative prediction error for all measurement points. SAE is determined by formula 2 :

$$
\mathrm{SAE}=\sum_{i=1}^{n}\left|U_{i}-a_{i}\right|
$$

where $U_{i}$ - value of the measured offset; $a_{i}$ - value of the predicted displacement. 
In addition to quantifying shifts, it is crucial for the algorithm to accurately recognize the sign of the shift (negative or positive). To assess the quality of this aspect, accuracy metrics are used, defined by formula 3 . This evaluation is based on the error matrices (Table 1).

$$
\text { accuracy }=\frac{T P+F N}{T P+F P+F N+T N}
$$

TABLE 1 - ERRORS MATRIX

\begin{tabular}{|c|c|c|}
\hline & $\mathbf{a}=\mathbf{1}$ & $\mathbf{a}=\mathbf{0}$ \\
\hline$\widehat{\boldsymbol{a}}=\mathbf{1}$ & True Positive (TP) & False Positive (FP) \\
\hline$\widehat{\boldsymbol{a}}=\mathbf{0}$ & False Negative (FN) & True Negative (TN) \\
\hline
\end{tabular}

Where a - the true offset sign label, $\hat{a}$ - the predicted value.

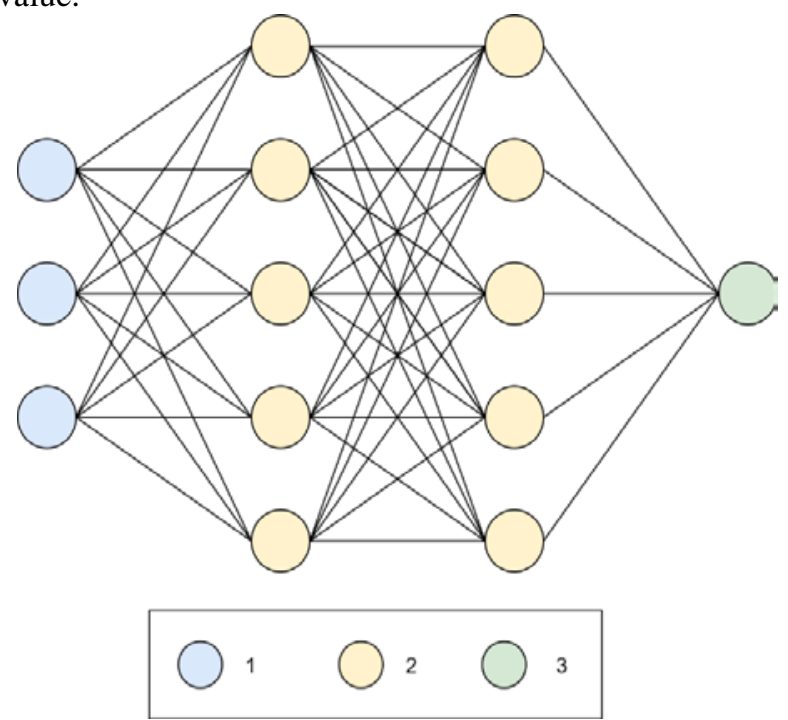

Fig. 3. Structure of artificial neural network. 1 - input layer neurons; 2 hidden layer neurons; 3 - output layer neuron.

\section{RESULTS AND DISCUSSION}

Figure 4 shows an illustration of the interpolation and extrapolation of the initial data of the velocities of east horizontal movements. Interpolation was performed by the inverse distance method, extrapolation by the artificial neural network method. The figure clearly shows the difference in the amount of data obtained. Neural network extrapolation allows us to obtain data for the southern part of the study area, where a large number of local and large regional tectonic structures are located.

Figure 5 and table 2 shows the results of spatial prediction compared with kriging and inverse distance methods on an enlarged scale for the construction site area underground research laboratory (URL).

TABLE 2 - METRICS

\begin{tabular}{|c|c|c|c|}
\hline \multirow{2}{*}{ Metrics } & \multicolumn{3}{|c|}{ Methods of spatial interpolation } \\
\cline { 2 - 4 } & $\begin{array}{c}\text { Inverse } \\
\text { distance }\end{array}$ & $\begin{array}{c}\text { Artificial } \\
\text { neural } \\
\text { network }\end{array}$ & Kriging \\
\hline SAE, mm & 65.02 & 13.36 & 59.58 \\
\hline MAE, mm & 10.84 & 2.23 & 9.93 \\
\hline Accuracy & 0.67 & 1 & 0.67 \\
\hline
\end{tabular}

The quality metrics show that the neural network algorithm is the most optimal for modeling the displacement and velocity fields of modern crustal movements. The SAE metric is almost 5 times lower than the other methods with a MAE of about $2.23 \mathrm{~mm}$ per point, which corresponds to the RMS of determining displacements and therefore reduces the unreliability of the simulation. Also, the neural network algorithm correctly recognized all directions of movement, accuracy $=1$, while the other methods have accuracy $=0.67$, which is significantly lower.

As a result of the algorithm, the maps-distributions of velocities of modern horizontal movements were obtained for the territory of the Nizhne-Kansk massif (Figs. 6-7). 
Environment. Technology. Resources. Rezekne, Latvia Proceedings of the $13^{\text {th }}$ International Scientific and Practical Conference. Volume 1, 162-169

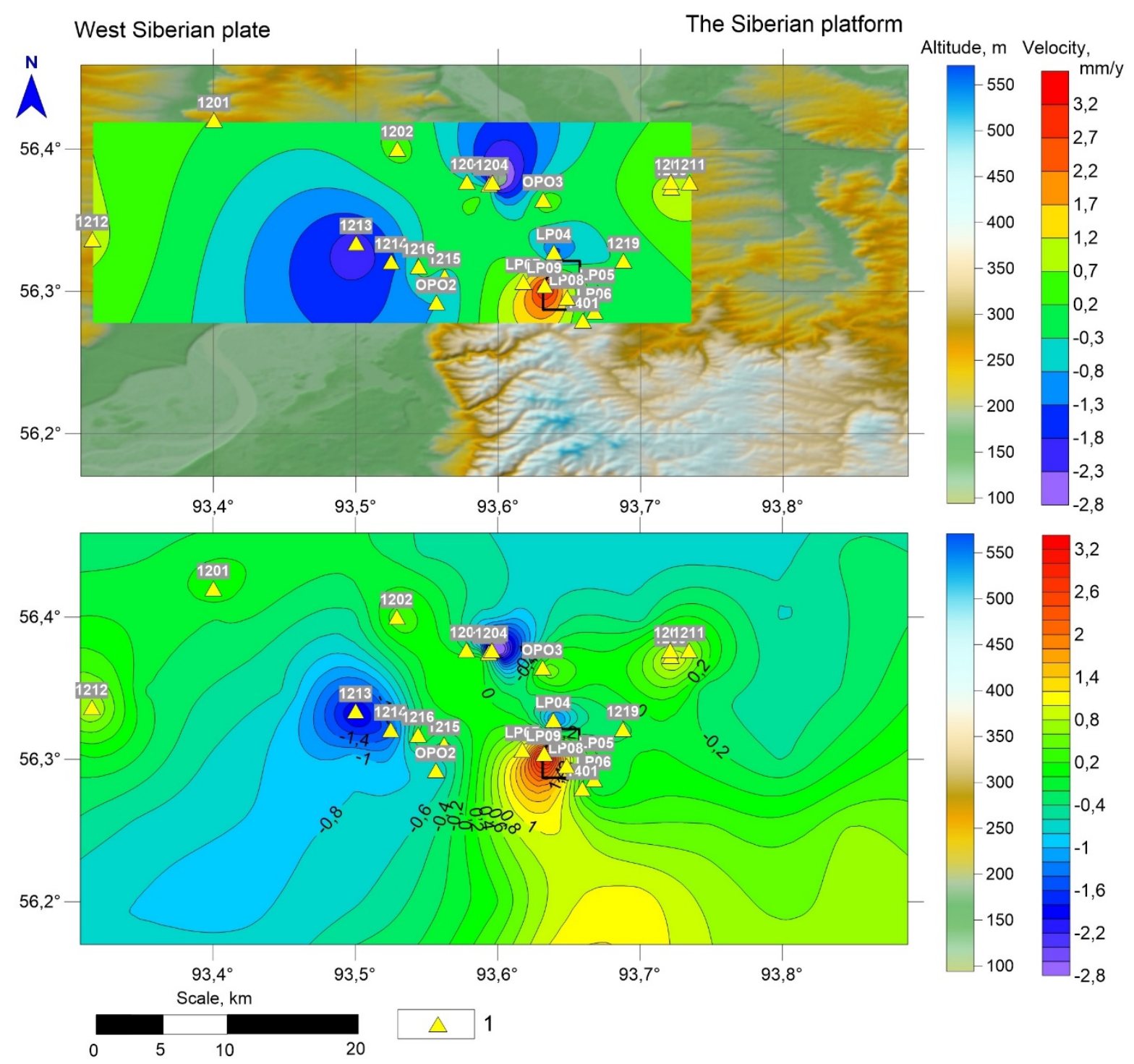

Fig. 4. Results of modelling the east velocities of modern horizontal movements of the Nizhne-Kansk massif by inverse distance and artificial neural network methods. 1 - GNSS points. 


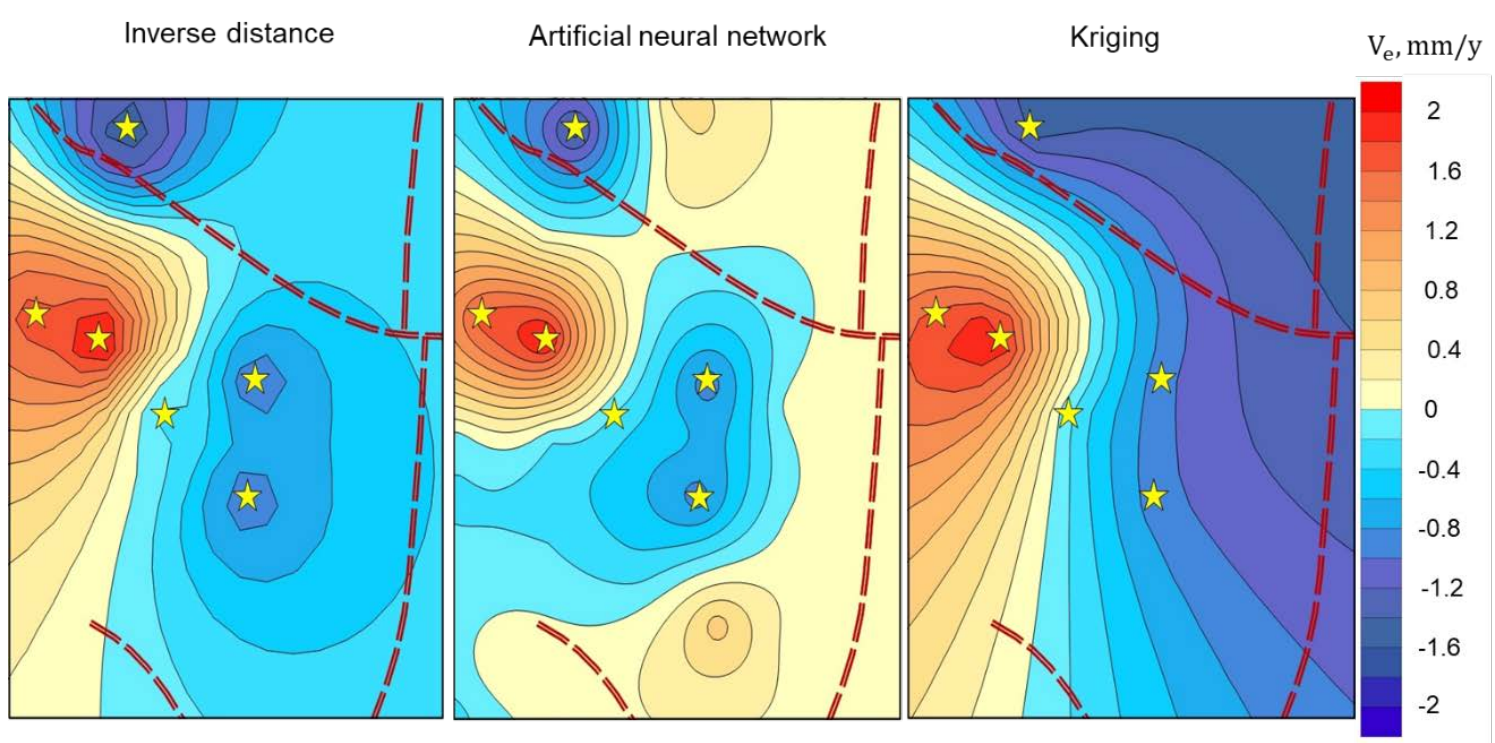

Fig. 5. Horizontal east velocity $\mathrm{V}_{\mathrm{e}}$ maps for the URL construction site area modelled by methods: inverse distance, kriging and artificial neural network.

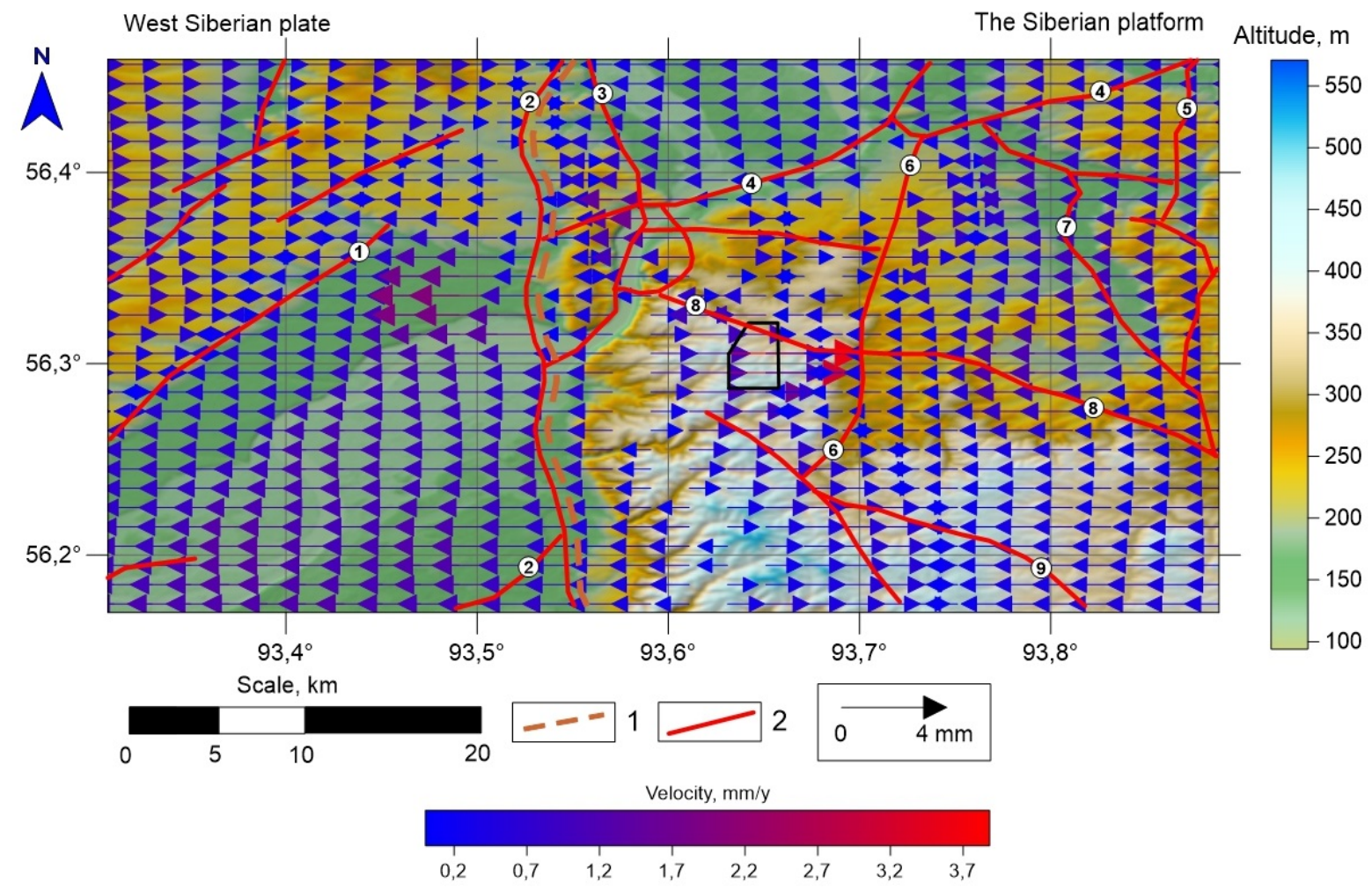

Fig. 6. The field of modern horizontal velocities of the Earth's crust in the east direction in the southern part of the Yenisei Ridge. 1 - contact boundary of Siberian platform and West Siberian plate; 2 - tectonic faults. 
Environment. Technology. Resources. Rezekne, Latvia

Proceedings of the $13^{\text {th }}$ International Scientific and Practical Conference. Volume 1, 162-169

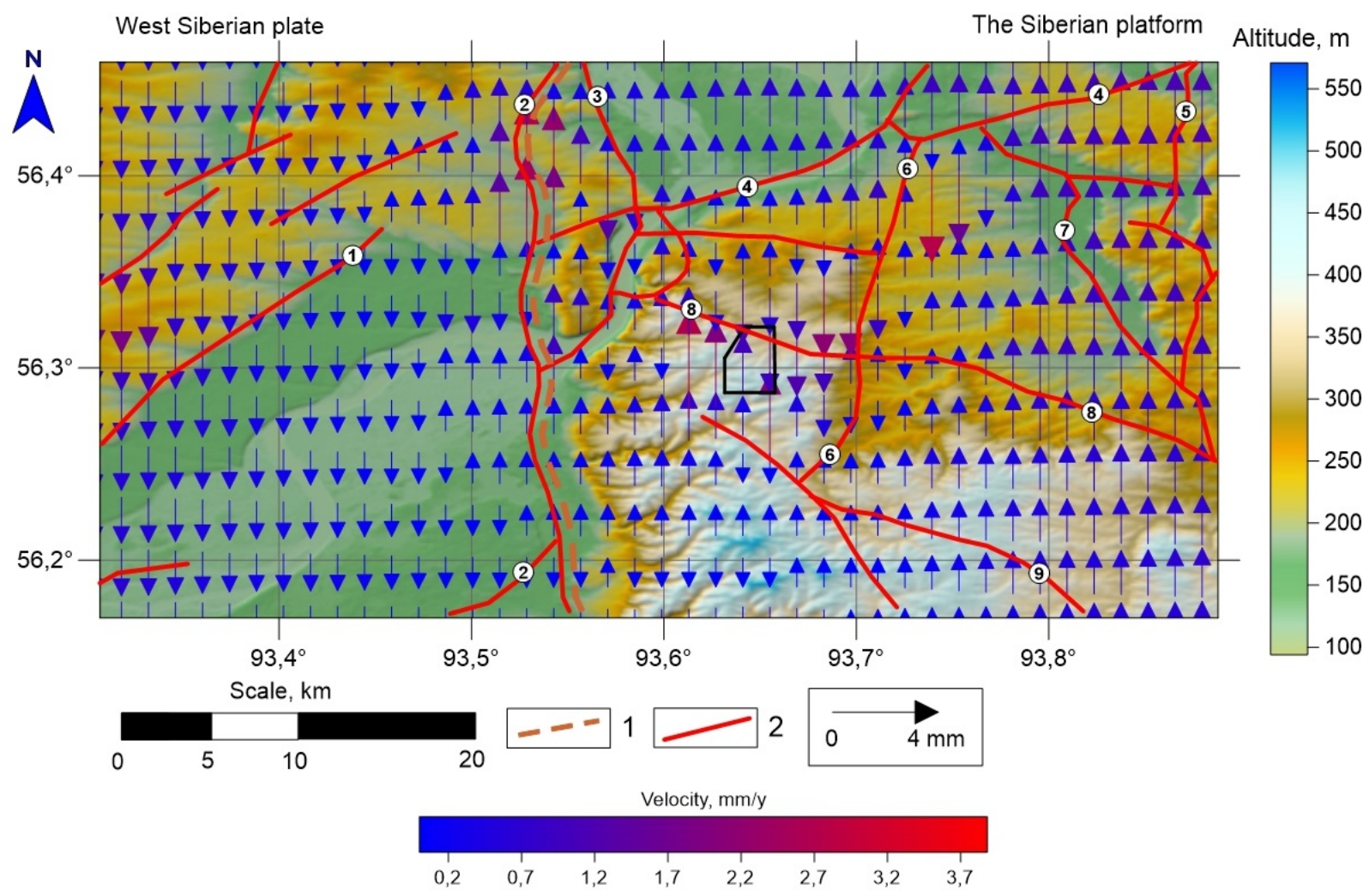

Fig. 7. The field of modern horizontal velocities of the Earth's crust in the north direction in the southern part of the Yenisei Ridge. 1 - contact boundary of Siberian platform and West Siberian plate; 2 - tectonic faults.

These are used to analyze the data. According to Figures 6 and 7, we can conclude that in the Central-Eastern part of the studied polygon, the most chaotic "picture" of the signs and magnitudes of movements was obtained.

\section{CONCLUSIONS}

As a result of modeling, new data were obtained, which were used to assess the geodynamic regime of the area. A more detailed analysis of the modeling results [4] showed good convergence with the results of geological studies [89]. The data obtained on the modern movements of the Earth's crust can be used for geodynamic zoning of the studied areas. It is possible to distinguish qualitative indicators - zones of tension and compression, calculate the tectonic component of stress in the rock massif, determine zones of high-gradient displacements, etc.

Spatial extrapolation based on the neural network approach allows us to cover the entire necessary area of the polygon and to investigate in more detail the current activity of local tectonic structures.

\section{ACKNOWLEDGMENTS}

This work was conducted in the framework of budgetary funding of the Geophysical Center of RAS, adopted by the Ministry of Science and Higher Education of the Russian Federation

\section{REFERENCES}

[1] Dorofeev A.N., Bolshov L. A., Linge I. I., Utkin S. S., Saveleva E. A. Strategic Master Plan for R\&D Demonstrating the Safety of Construction, Operation and Closure of a Deep Geological Disposal Facility for Radioactive Waste // Radioactive Waste. 2017. № 1. p. 32-41. (In Russian).

[2] Kaftan V.I., Gvishiani A.D., Morozov V.N., Tatarinov V.N Methods and results of determination of movements and deformations of the Earth's crust according to GNSS data at the Nizhne-Kansk geodynamic test network in the area of radioactive waste disposal // Sovremennye Problemy Distantsionnogo Zondirovaniya Zemli iz Kosmosa. 2019. №1. p. 83-94. DOI: 10.21046/2070-7401-2019-16-83-94.

[3] Tatarinov V.N., Morozov V.N., Kaftan V.I., Manevich A.I. Modern geodynamics of the southern of the Yenisei ridge derived from the results of satellite observations // Geophysical research. 2018. Vol.19. No.4. p. 65-79. DOI: 10.21455/gr2018.4-5.

[4] Gvishiani A.D., Tatarinov V.N., Kaftan V.I., Manevich A.I., Dzeboev B.A., Losev I.V. The velocities of modern horizontal movements of Earth crust in the South sector of Yenisei ridge according to GNSS observations // Doklady Earth Sciences. 2020. Vol. 493. №1. p. 73-77. DOI: 10.1134/S1028334X20070077.

[5] Wu J., Tang C., Chen Y. Effect of triangle shape factor on precision of crustal deformation calculated // Journal of Geodesy and Geodynamics. 2003. Vol. 23(3). p. 26-30. (in Chinese).

[6] Dokukin P.A., Kaftan V.I., Krasnoperov R.I. Influence of triangle shape in geodetic network on the results of definition of Earth surface deformations // Izvestiya vuzov. Geodeziya i aerofotosemka = Proceedings of universities. Geodesy and aerophotography. 2010. No. 5. p. 6-11.

[7] Markovich K.I. Influence of the configuration of final elements on the accuracy of determination of the components of deformation // Vestnik SSUGT (Siberian State University of Geosystems and 
Alexandr Manevich, et al. Modelling the Horizontal Velocity Field of the Nizhne-Kansk Massif According to GNSS

Observations

Technologies). 2019. Vol. 24. №3. p. 37-51. https://doi.org/10.33764/2411-1759-2019-24-3-37-51. [in Russian]

[8] Lobatskaya R.M. Neotectonic fault-block structure of junction of Siberian platform and West Siberian plate // Russian Geology and Geophysics. 2005. T.46. №2. p. 141-150.
[9] Kolmogorova P.P., Kolmogorov V.G. Modern vertical movements of the Earth's crust of the Yenisei ridge // Russian Geology and Geophysics. 2004. T.45. №4. p. 455-466. 